\title{
Energy Analysis of A Hybrid Wind-Wave Solution For Remote Islands
}

\author{
Spyridon Trikalitis (D), George Lavidas, and John K. Kaldellis \\ Laboratory of Soft Energy Applications \& Environmental Protection, Department of Mechanical Engineering, \\ University of West Attica
}

Received: 6 July 2021 / Received in final form: 1 September 2021 / Accepted: 1 September 2021

\begin{abstract}
The energy needs of most Aegean islands are covered by the operation of autonomous/local power stations (APS/LPS) using imported oil. The costly operation of the APS/LPS combined with the resulting environmental problems, set the issue of a sustainable and rational energy solution mainly for the remote islands, showing respect to the sensitive island ecosystems and the acceptance of local communities. In this context, high wind speeds as well as the remarkable wave potential of the Aegean Archipelagos could be the driving force for a sustainable energy supply solution for these islands by exploiting combined energy sources along with an appropriate energy storage system, comprising a modern hybrid renewable based station. Moreover, the exploitation of wave energy is one of the future priorities of the European Union (Blue Growth) in an effort to support the installation of wave energy converters, which are in the final stage of technological development. The proposed analysis examines the combined exploitation of the wave and wind potential for a representative medium sized island of the Aegean Archipelagos in order to cover its electrical needs. The results show that the installation of a hybrid power station contributes to a higher integration of renewable energy systems (RES) into an autonomous micro-grid and that the stochastic production of wind turbines can be counterbalanced due to the smoother (time-dependent) production of wave systems. In addition, the ability to store excess renewable energy enhances the energy supply security of an island micro-grid providing a clean energy solution for the remote Aegean island communities and thus reducing their oil dependence.
\end{abstract}

\section{Introduction}

\subsection{Energy status of remote islands}

The numerous Greek islands located in the Aegean Archipelagos, have been electrified to date by autonomous thermal power stations (APS), not only consuming significant amounts of imported oil but also suggesting that the Greek society subsidizes the extra costs of oilbased power generation via services of general interests (SGIs or $\Upsilon K \Omega$ in Greek) [1].

Entering the year 2021, there are plans concerning underwater cable interconnections of the remote islands with the mainland. However, this is a solution that will not apply for all islands, as some are quite remote and/or present low levels of energy demand, which normally makes interconnection projects a less attractive option. Having that in mind, use of renewable energy installations, especially in the Aegean, where one may encounter excellent solar potential, high-quality wind potential and

\footnotetext{
* e-mail: spyrtrik@gmail.com
}

in certain cases appreciable wave potential, stands as a promising solution for the electrification of local remote communities at reasonable cost [2].

On the other hand, RES shares have up to now been limited to $\sim 15 \%$ in the area of Aegean Sea islands, which results from both the intermittent character of wind and solar power generation, and the inherent technical limitations of island grid systems. As such, development of RES-based hybrid power stations, supported by energy storage systems introduce an interesting alternative. To that end, in the current study we examine the solution of a hybrid wind-wave storage station using a typical, medium scale island case in the Aegean Sea, and focusing on the energy analysis of the proposed scheme.

\section{Amorgos island electricity status}

The island of interest corresponds to the island of Amorgos, belonging to the complex of Cyclades in the Aegean Sea region. In the following sections, presentation of the local wind and wave potential of the island is made, together with a description of the current electricity status of the island. 


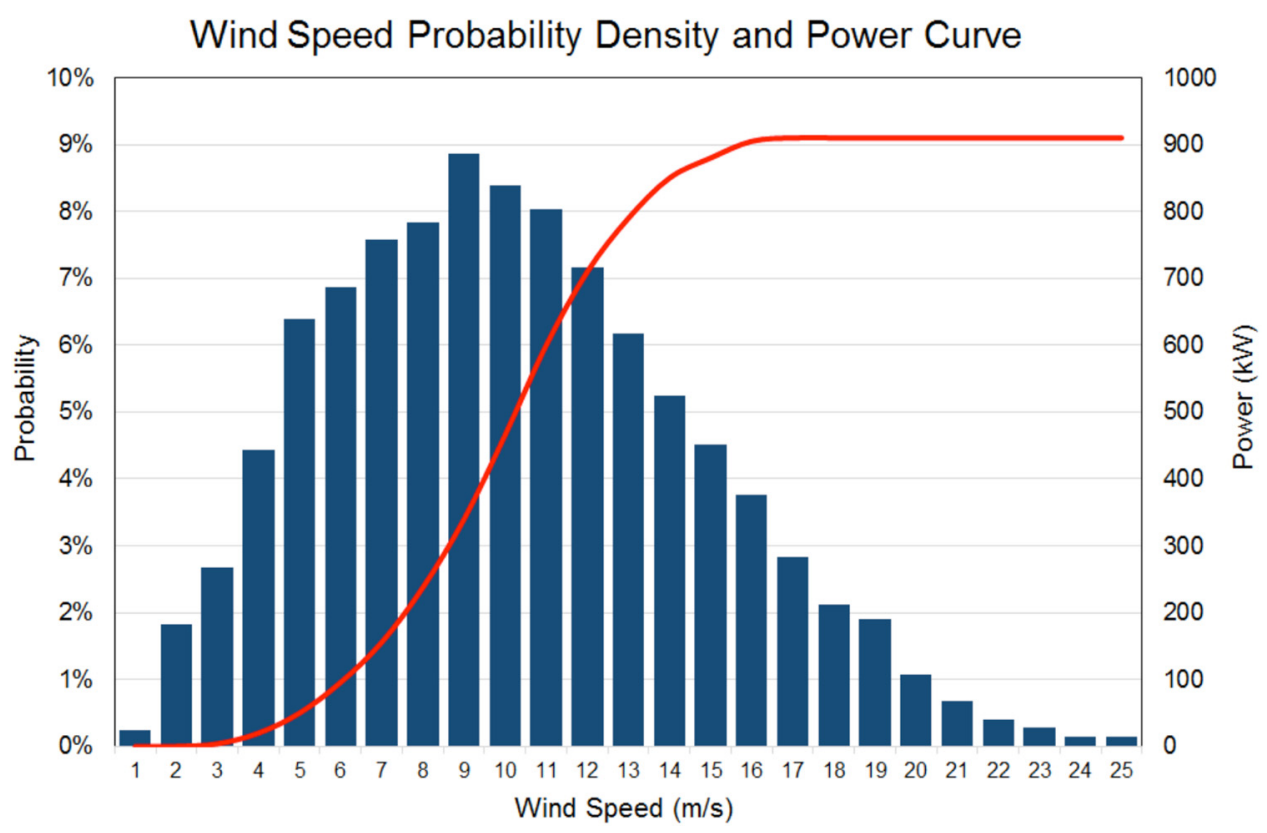

Fig. 1. Wind speed probability density for Amorgos island vs. E-44 WT power curve.

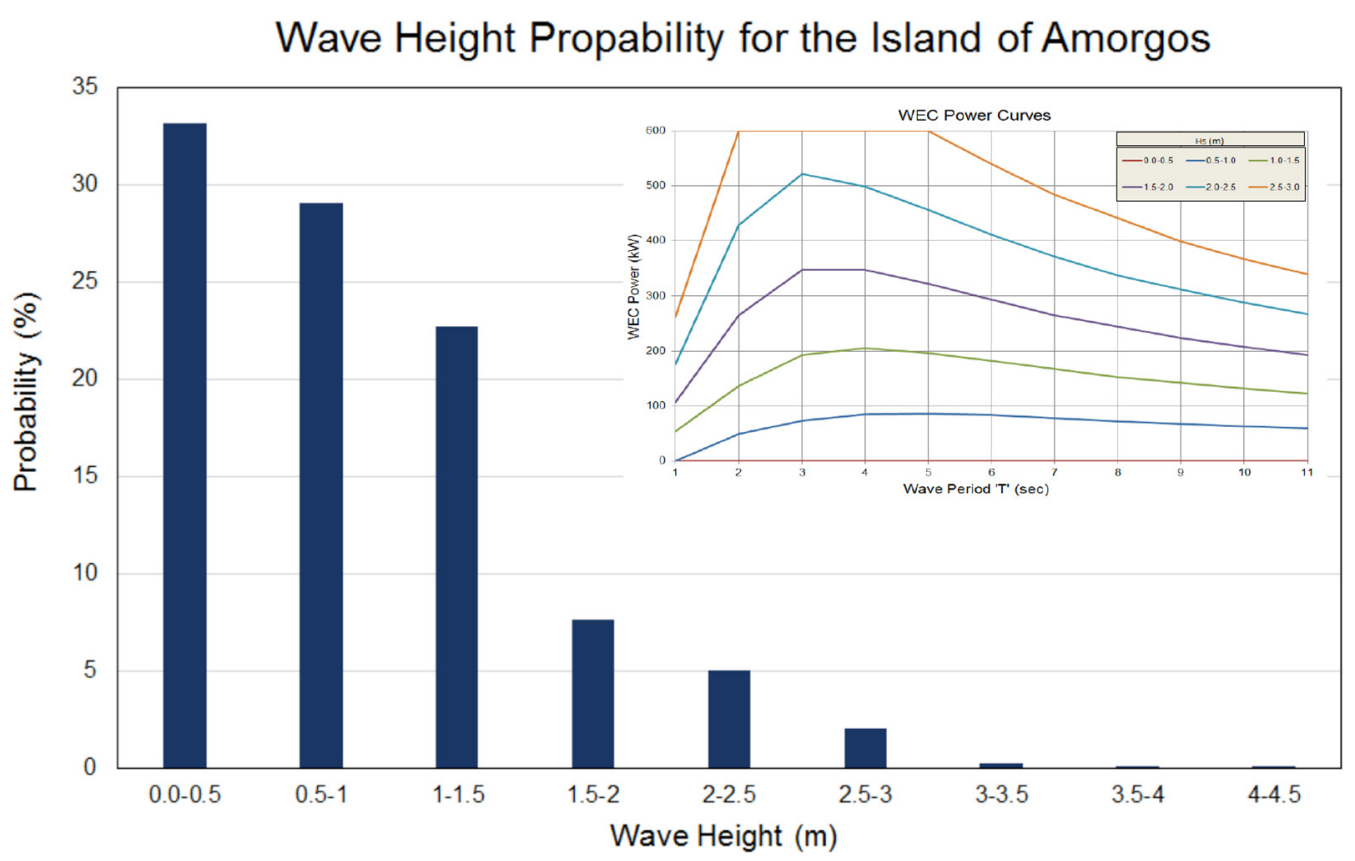

Fig. 2. Wave potential characteristics vs. wave converter power curves.

\subsection{Wind and wave potential}

Wind potential on the island of Amorgos is of high-quality. This is better reflected in the distribution of Figure 1, resulting from the processing of detailed local wind speed measurements at $10 \mathrm{~m}$ height, extrapolated at $45 \mathrm{~m}$ height (selected wind turbine hub height). Average wind speed to that end on an annual basis is found to exceed $9.5 \mathrm{~m} / \mathrm{s}$. Besides, and in the same figure, one may also find the respective wind power curve selected, compared against the respective wind speed distribution.
Concerning the wave potential, the data have been obtained from the Hellenic Center of Marine Research [3], and more specifically from the Poseidon database, which includes data regarding the significant wave height $H_{s}$, the maximum wave height $H_{\max }$, the wave direction, the wave period $T_{s}$ and finally the peak wave period $T_{p}$. The latter have been collected for the area of Amorgos and for an entire year, on a three hour step. To that end, in Figure 2, one may find the respective probability distribution concerning the significant wave height, alongside the power curves of the selected wave converter. 


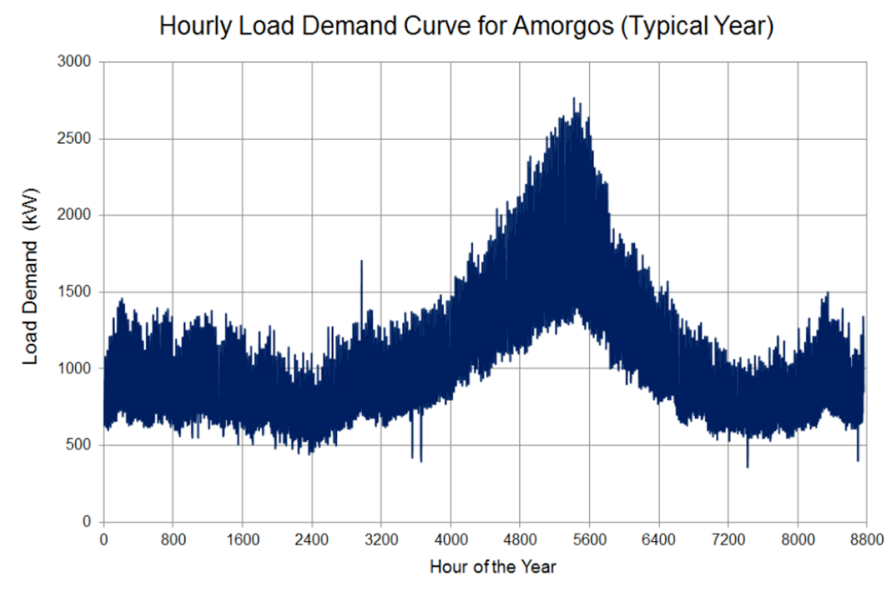

Fig. 3. The annual load demand of Amorgos island.

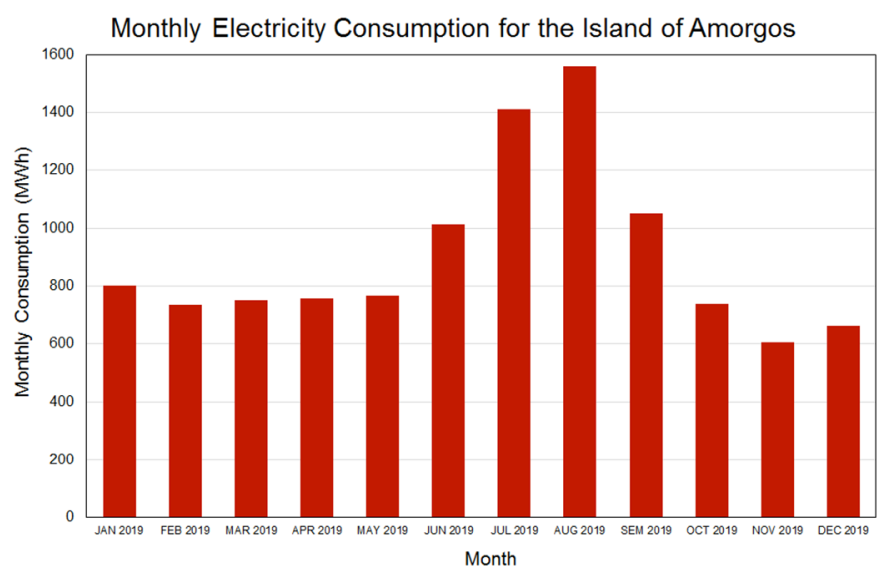

Fig. 4. Amorgos island monthly energy consumption.

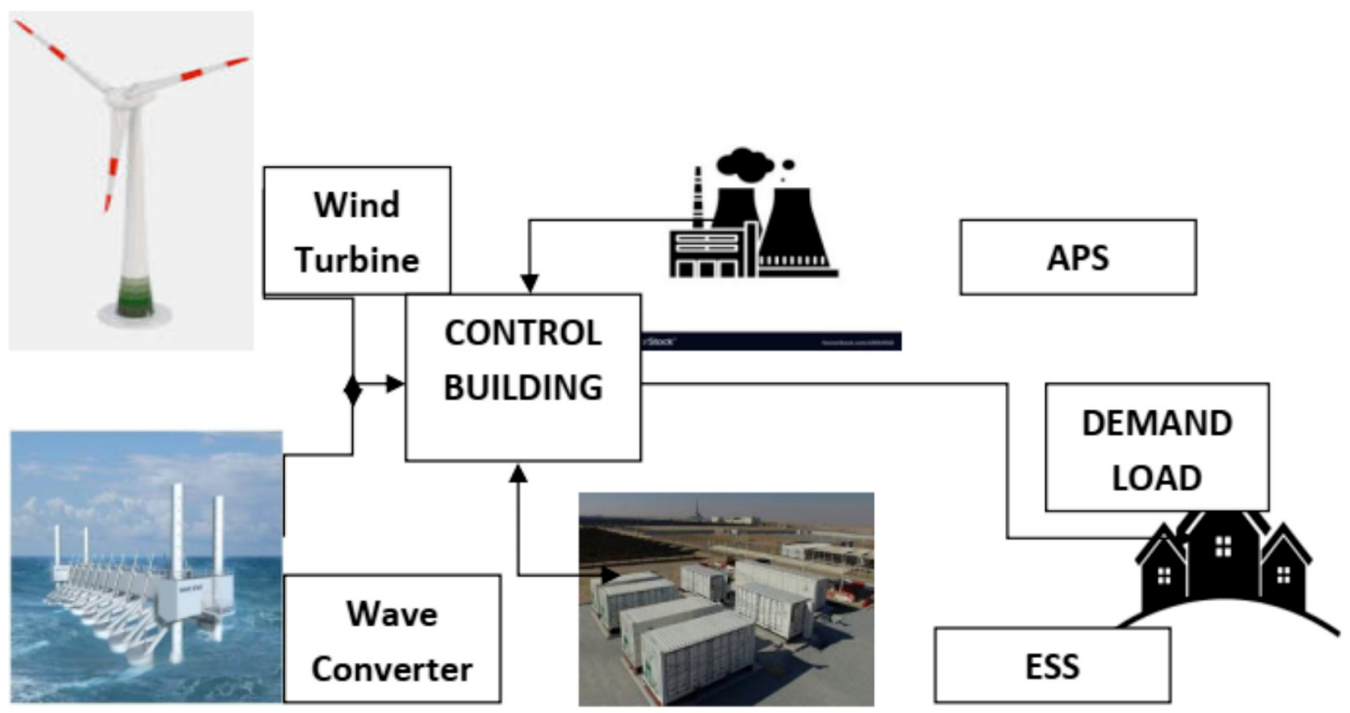

Fig. 5. Schematic representation of the proposed hybrid power installation.

\subsection{Load demand}

Next, in Figure 3, we also present the hourly-basis load demand curve of the island, also for an entire year, while the respective monthly distribution is given in Figure 4. At the same time, it should be noted that the installed capacity of the local power station is $6 \mathrm{MW}$, based on the operation of the nine diesel generators of nominal power between $100 \mathrm{~kW}$ and $1 \mathrm{MW}$. In this context, annual oil consumption for the purpose of electricity generation amounts to $\sim 2000$ tons per year with the respective operational and total electricity generation cost amounting to $250 € / \mathrm{MWh}$ and $371 € / \mathrm{MWh}$ respectively $[1,4]$.

\section{Proposed solution and methods}

In this part of the research, the proposed solution is presented (Fig. 5). The primary target of the proposed solution is to minimize the dependence of the local grid on oil imports and to maximize local RES penetration. In order to obtain the most suitable configuration, the criteria examined depend on the target that one may set. More specifically the proposed solution is composed by two RES-based units in cooperation with a battery energy storage system, while the existing APS will be used only as a backup solution in case of extremely high demand periods.

In more detail, the proposed hybrid power installation is based on one or more appropriate wind turbines, one or more wave power converters and a battery storage system. Taking into account the existing wind potential and the weak grid characteristics, the smallest available variable speed wind turbine (Enercon E-44) is selected. This is arguably the biggest-size wind turbine that may be installed in Amorgos island due to the local infrastructure limitations. The rated power of E-44 wind turbine is $900 \mathrm{~kW}$, while the hub height is 45 meters, with respective the wind turbine power curve presented in Figure 1. Taking into consideration the wind speed density probability profile and using the wind turbine technical characteristics, 


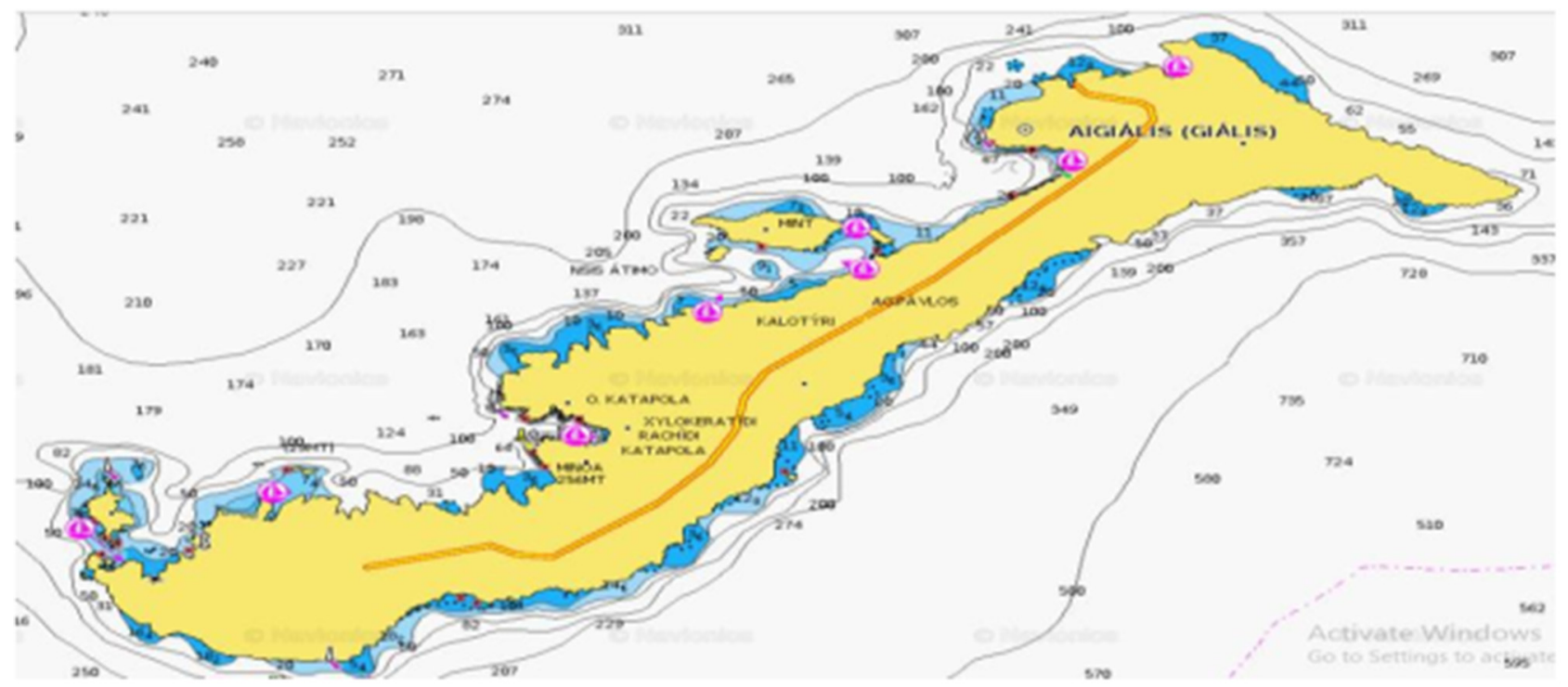

Fig. 6. Bathymetric map of Amorgos [9].

the respective annual yield may by estimated applying equation (1).

$$
E_{\text {year }}=\Delta t_{\text {year }} \times P \times C F .
$$

Note that the capacity factor of the proposed installation is given by equation (2), where the mean power coefficient $\omega$ is given by equation (3) and the parameter $\Delta$ describes the mean technical availability of the installation, assumed equal to 95\%. This last value is in accordance with the fact that the wind turbines will be installed at a remote island. To this end, the estimated annual energy production is approximately $3.58 \mathrm{GWh}$, while the corresponding capacity factor $C F$ is almost $45 \%$.

$$
\begin{gathered}
C F=\omega * \Delta \\
\omega=\int_{V_{c}}^{V_{f}} \frac{P_{V}}{P_{0}} \times f(V) \times d V .
\end{gathered}
$$

On top of the high-quality wind potential of several Greek islands, the wave potential of the Aegean Sea is also quite significant and amongst the highest across the Mediterranean $[5,6]$. In more detail, the overall technically exploitable wave potential for EU states is estimated at 150-230 TWh/year, while the respective of Greek Seas is estimated at 4-11 TWh/year [7]. The respective wavedriven power generation may be calculated by equation (4).

$$
P=\rho \times g^{2} \times H_{S}^{2} \times T_{e} /(64 \times \pi)
$$

where $\rho$ is the density of sea water, equal to $1026 \mathrm{~kg} / \mathrm{m}^{3}, H_{s}$ is the significant wave height and $T_{e}$ is the energy period [8]. Moreover, Figure 6 presents the bathymetric map for the broader area of Amorgos, allowing for the preliminary determination of installation sites for the selected wave converter (e.g. WaveStar $600 \mathrm{~kW}$ ). The latter was selected due to its better performance in medium wave potential conditions, with wave converters like Pelamis known for performing better in open seas.

To that end, equation (4) may be used in order to calculate the expected annual energy from the wave converter selected. Using the power curve of WaveStar, the expected annual yield is approximately $E_{\text {wave }}=25 \mathrm{MWh} / \mathrm{m}$, with Figure 2 presenting the power curve of the device in relation to the wave height. Indicatively, and using Figure 2 which is given by the manufacturer and the corresponding wave height and wave period values, the annual produced energy from one wave converter is calculated at almost $E_{\text {year }}=1.1 \mathrm{GWh}$, thus the calculated capacity factor is $\mathrm{CF}_{\text {wave }}=21 \%$.

The third component of the new installation is the battery storage system, which could consider different types of batteries, e.g. NaS. A similar battery system is currently considered (Fig. 7), which consists of separate modules, with each one carrying a rated output of $33 \mathrm{~kW} /$ $200 \mathrm{kWh}$. Combining six of them together, a container is built up which carries an overall output and capacity of $200 \mathrm{~kW}$ and $1200 \mathrm{kWh}[10]$.

For the estimation of the battery capacity vs. the hourly (useful) energy output of the battery, one may use equation (5) [11], i.e.:

$$
Q_{\max }=\left(E_{d} * h\right) /\left(\Delta t * D O D_{l} * n_{\text {disch }} * U\right)
$$

where $E_{h}$ (approximately $9 \mathrm{GWh} /$ year) is the total energy demand of the proposed installation and $h$ is the number of energy autonomy hours desired, while $\Delta t=8760 \mathrm{~h}$ per year, $\mathrm{DOD}_{\max }=75 \%, n_{\text {disch }}=0.96$ and $U=220 \mathrm{~V}$.

Finally, using commercial battery models available, the discharging output rated power and the storage system capacity values to be examined are the following:

- $1 \mathrm{MW} / 6 \mathrm{MWh}$, with maximum autonomy $6 \mathrm{~h}$.

- $2 \mathrm{MW} / 12 \mathrm{MWh}$, with maximum autonomy $12 \mathrm{~h}$.

$-3 \mathrm{MW} / 18 \mathrm{MWh}$, with maximum autonomy $18 \mathrm{~h}$. 


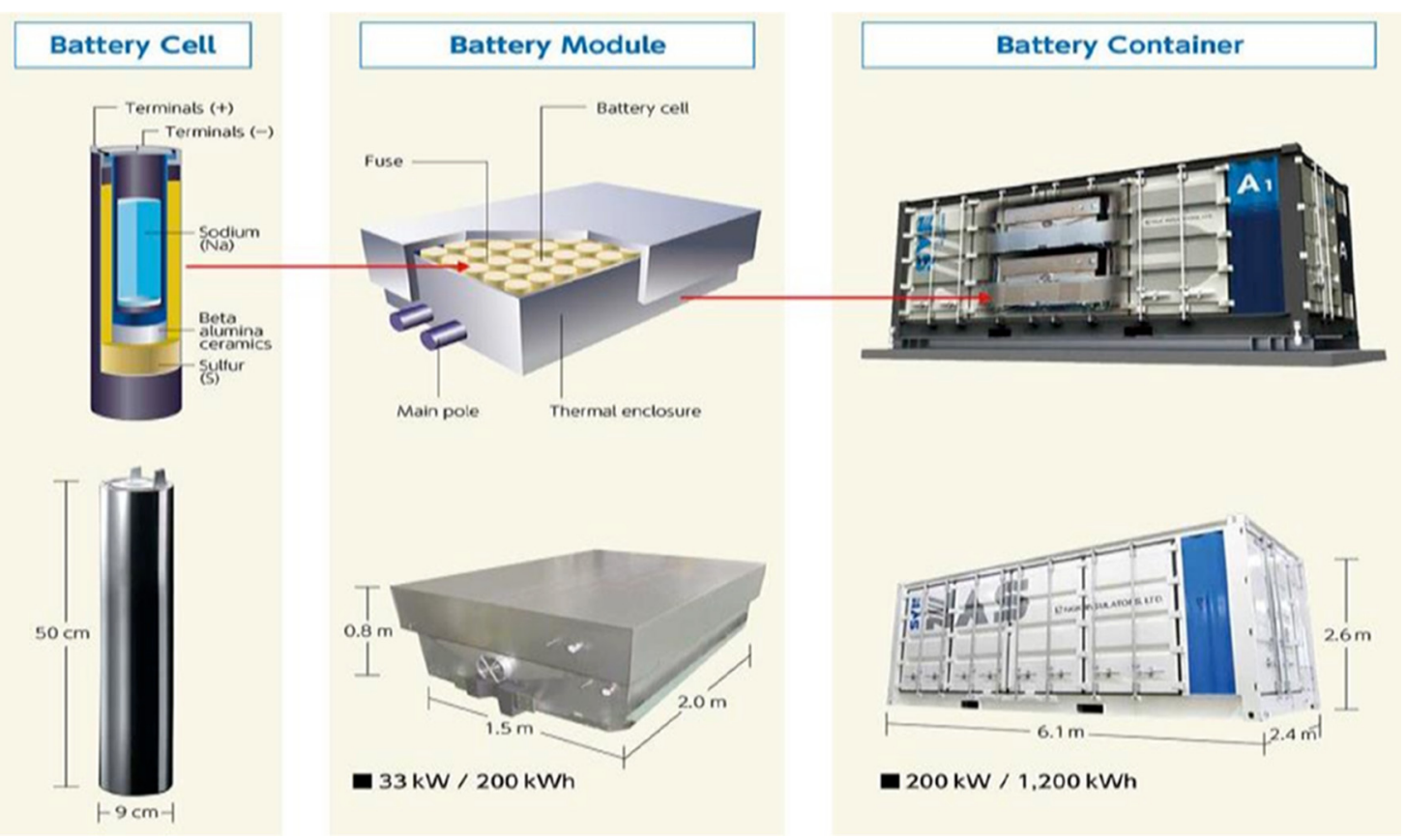

Fig. 7. NaS battery storage system.

- $4 \mathrm{MW} / 24 \mathrm{MWh}$, with maximum autonomy $24 \mathrm{~h}$.

- $6 \mathrm{MW} / 36 \mathrm{MWh}$, with maximum autonomy $36 \mathrm{~h}$.

- $8 \mathrm{MW} / 48 \mathrm{MWh}$, with maximum autonomy $48 \mathrm{~h}$.

For most Greek islands, the load profile is characterized by a quite variable distribution, i.e. high power demand during summer (mainly due to tourism) while for the rest of the year the load demand presents little variation and is quite lower. This is also valid for the case of Amorgos, where the peak load demand during August is almost 2.8 MW, while the average load demand is slightly higher than $1 \mathrm{MW}$ [4]. In Table 1, one may find additional information about the main characteristics of the Amorgos island annual load demand.

After the analysis of the original data, we proceed to calculate the hybrid power station energy production, the battery storage state of charge (SOC) and any load deficit for several representative case studies, based on selected installed wind and wave power and battery capacity. For this purpose, an integrated computational frame has been developed. Actually, for every wind turbine and wave converter rated power selected the expected energy yield is estimated on the basis of the available wind and wave potential for the corresponding time period. In order to obtain a preliminary picture of the power balance between one E-44 wind turbine, one Wavestar-600 wave converter and the local grid load demand one may use Figure 8, for an entire year.

Accordingly, using the available local network information (e.g. peak load of the island of $\sim 2.8 \mathrm{MW}$, annual energy needs of $\sim 9$ GWh), the energy balance analysis is carried out for a selected number of combinations between RES-rated power and battery energy capacity [12]. More specifically, due to the electrical energy characteristics of
Table 1. Seasonal load demand information.

\begin{tabular}{lcl}
\hline Parameter & Load & Period \\
\hline Average hourly demand (MWh) & 1.05 & - \\
Average daily demand (MWh) & 24.1 & - \\
MAX hourly demand (MWh) & 2.76 & August \\
MIN hourly demand (MWh) & 0.36 & November \\
MAX daily demand (MWh) & 45.61 & August \\
MIN daily demand (MWh) & 15.12 & April \\
\hline
\end{tabular}

the island and the selected commercial wind and wave converters power curves, six (6) representative cases have been selected. Subsequently each of the above cases are combined with another six (6) configurations depending on the battery storage capacity selected, i.e. finally 36 $(=6 \times 6)$ scenarios are investigated, all of them corresponding to equipment components existing in the market.

For each one of the 36 cases the expected RES production, the corresponding deficit/surplus, the battery SOC and the island energy autonomy and energy surplus are calculated. For this purpose, the algorithm of Figure 9 is implemented, where the energy flow through the installation components is presented. More specifically:

- If the RES-based energy production is higher than the energy demand for each specific time period analyzed then the energy production is covering the grid demand and the energy surplus charges the system batteries. In case that the batteries are full, the energy surplus feeds secondary priority loads. 


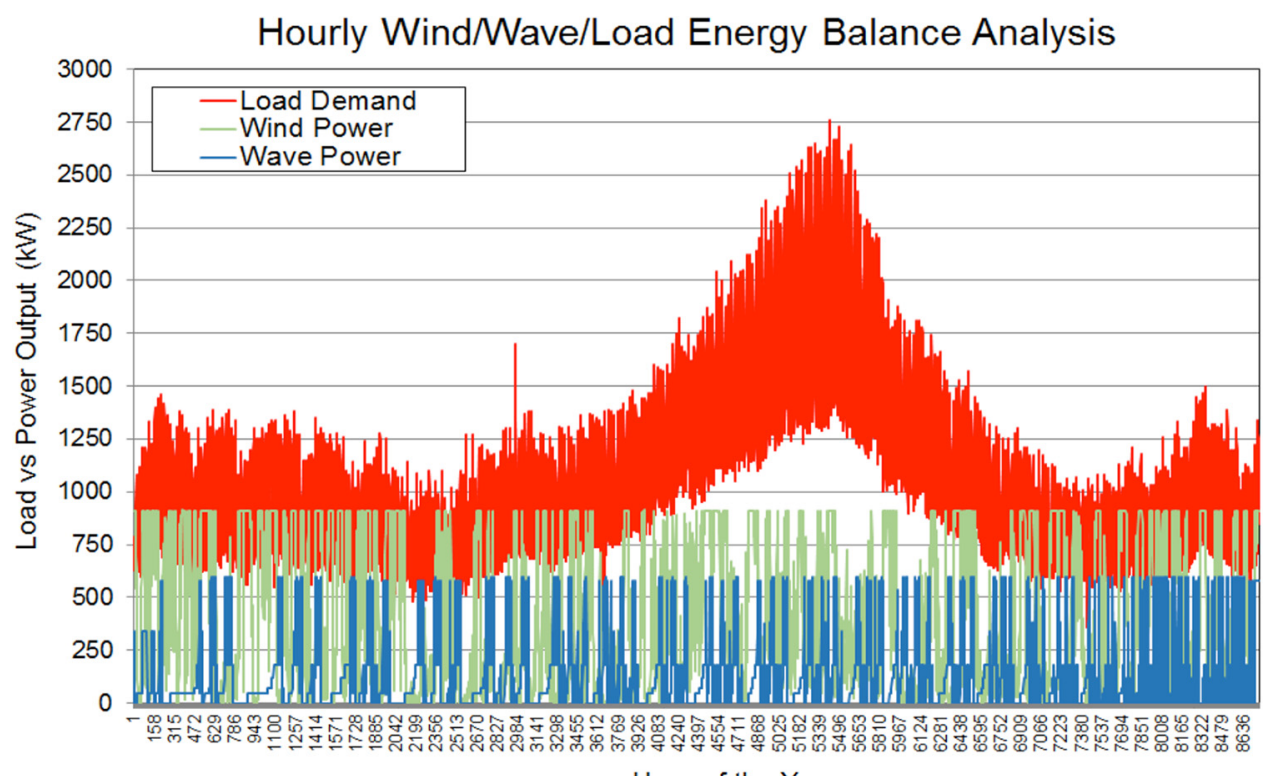

Hour of the Year

Fig. 8. Hourly production/demand energy balance (single wind turbine and wave converter).

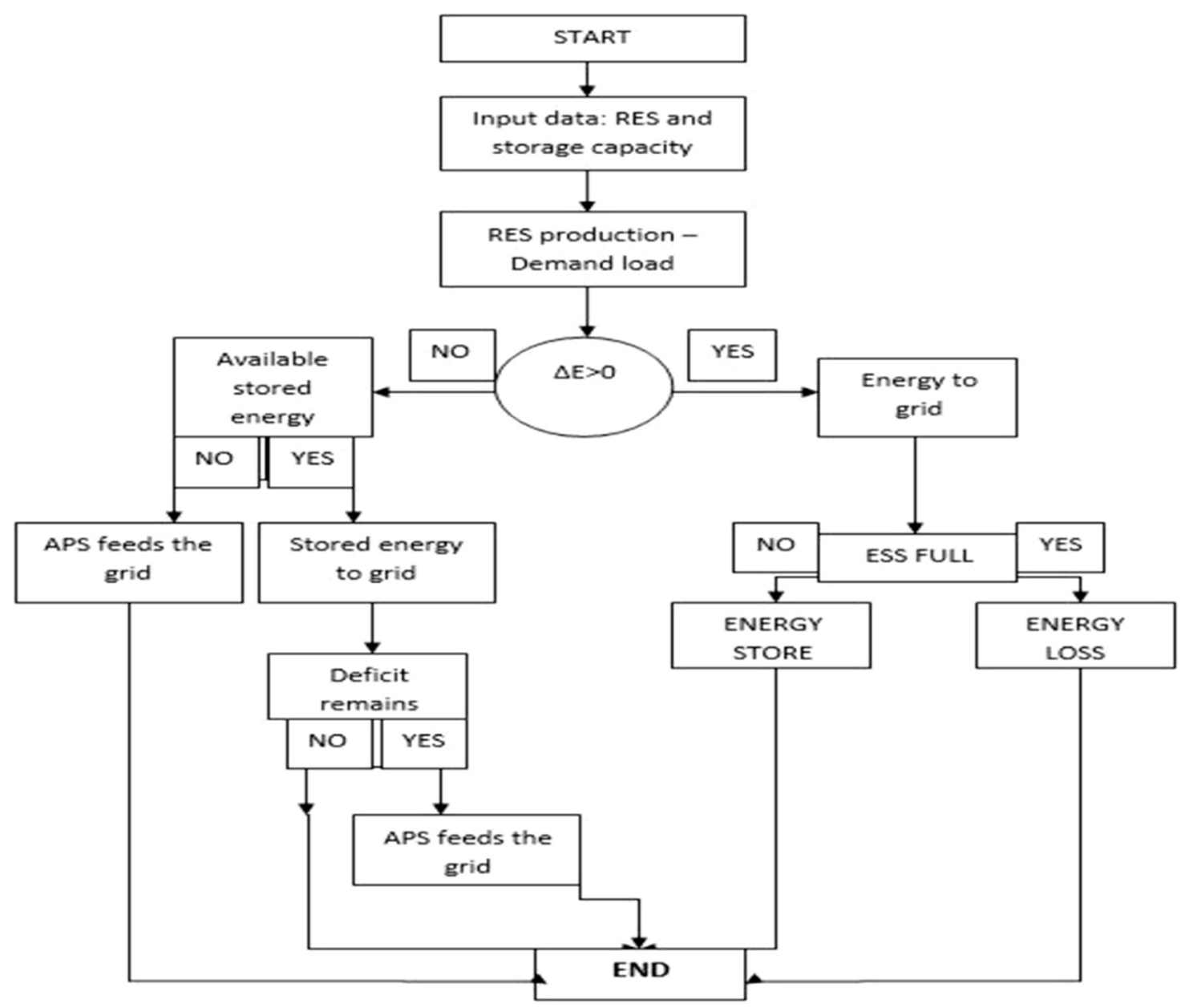

Fig. 9. Energy flow diagram. 
- If the RES-based energy production is lower than the energy demand, then the energy production covers partially the grid demand and the power deficit is covered by the batteries. In case that the batteries are near their minimum permitted SOC $\left(\mathrm{DOD}_{\max }=75 \%\right)$ then the thermal power station of the island covers (under a specific dispatch plan) the power deficit using imported diesel oil.

Once the algorithm is executed for each case study analyzed, an accurate energy balance analysis is available including the contribution of the local APS. Furthermore, an analytical financial study is also necessary in order to evaluate the economic performance of each scenario examined. However, such a cost-benefit analysis is out of the scope of the present study. On the other hand, one may estimate the avoided carbon dioxide and air pollutants' emissions due to the operation of the proposed hybrid power station.

As mentioned earlier, one of the main aims of the study is the energy analysis of the proposed configuration. The latter is currently configured so as to present different aspects of the energy balance, expressed by the following formula that returns the accruing surplus (or deficit) for each of the examined system scenarios and on an annual basis, considering that the former may be also used for the coverage of secondary loads, such as with the operation of a desalination plant [13] under construction.

$$
E_{\text {SURPLUS } / \text { DEFICIT }}=E_{\text {PROD }}-E_{\text {DEMAND }}
$$

Moreover, environmental benefits accruing from the operation of such hybrid configurations, as a result of limiting the shares of oil-based power generation, are also estimated and presented. For this purpose, one takes into account the specific consumption of the thermal power station of Amorgos ( $\mathrm{gr} / \mathrm{kWh}$ ) together with the relevant emission factors and the RES contribution to the local grid for each case (from the $6 \times 6$ ) investigated.

Results of the overall analysis are next organized and presented in the form of explanatory graphs for each of the examined scenarios (see Figs. 10-15).

\section{Application results}

In relation to the above, presentation of application results is undertaken in the current section on the basis of a parametric analysis reflecting on the scenarios examined.

In this context, Figure 10 shows the energy contribution of each system component to the annual electricity supply for the first case examined (Case 1). As seen, the scenario assuming only Wavestar converters manages to cover less than half of the annual demand, with almost $2 \mathrm{GWh}$ produced to be wasted due to the mismatch between demand and supply. On the other hand, in the scenario with a 48 hours battery storage, the installation manages to cover more than half of the energy demand, as well as to take full advantage of the total energy produced, with the total losses being negligible $(\sim 24 \mathrm{MWh})$.
Moreover, Figure 11 shows the energy contribution of each component for Case 2, where wind power is also introduced. By using only the wind and wave converters, the installation already covers $\sim 60 \%$ of the annual energy demand. This time the surplus energy (energy that will be rejected) is above $2 \mathrm{GWh}$ for the scenario with no battery storage and it ends up to cover another $20 \%$ of the annual energy demand for the last scenario of 48 hours storage capacity.

Next, Figure 12 shows the energy contribution for each component of Case 3 , under which RES capacity is further increased. Starting with the scenario with no battery storage, the energy autonomy reaches $70 \%$ of the annual energy demand, which is reflective of the complementarily between wind and wave energy production, but with 4 GWh of wasted energy. On the other hand, if the maximum storage capacity is also introduced $(48 \mathrm{~h})$, the energy autonomy reaches $90 \%$ of the energy demand and the energy surplus is decreased at 2 GWh due to the battery storage system.

Accordingly, Figure 13 shows the energy contribution of each component for Case 4. For the particular case the annual energy autonomy increases to $75 \%$ for the scenario with no batteries, and the maximum scenario of storage capacity reaches an autonomy of $95 \%$. Even though there is a slight increase in the autonomy offered by the hybrid installation, the annual energy curtailed exceeds $6 \mathrm{GWh}$ if no batteries are considered, and is in the order of $4 \mathrm{GWh}$ with 48 hours of storage.

To that end, and in order to avoid system overdimensioning, the next case examines a different combination of wind and wave converters. In more detail, Figure 14 presents results for Case 5, where the battery-less configuration achieves autonomy levels that even exceed $70 \%$, with results further improving with the presence of storage, producing at the same time reduced levels of rejected energy. Such results are illustrative of the strong complementarily between the local wind and wave resources.

Finally, Case 6, presented in Figure 15, is as expected demonstrating the highest energy autonomy. It reaches almost $80 \%$ with no battery storage and $97 \%$ with 48 hours of battery storage. However, the specific case introduces very high levels of curtailed energy. In fact, for the first scenario, there are almost $15 \mathrm{GWh}$ and for the last one $12.8 \mathrm{GWh}$ of curtailed energy that can cover almost one and a half times the current annual demand of the island. This also reflects on the different $C F$ as well as on the pattern of energy generation that describe the component of wind power in comparison to the respective wave component.

Analyzing with more detail the results of Figure 12 one may estimate, on top of the energy balance already presented, the monthly oil-based energy production by the original thermal power station (TPS) in comparison with the corresponding oil-based energy production for Case 3, using all six battery storage configurations investigated, Figure 16. As it is obvious the energy production of the existing TPS is drastically decreased in case that the windwave-battery hybrid power station is in operation in Amorgos island, reducing the annual oil consumption by 


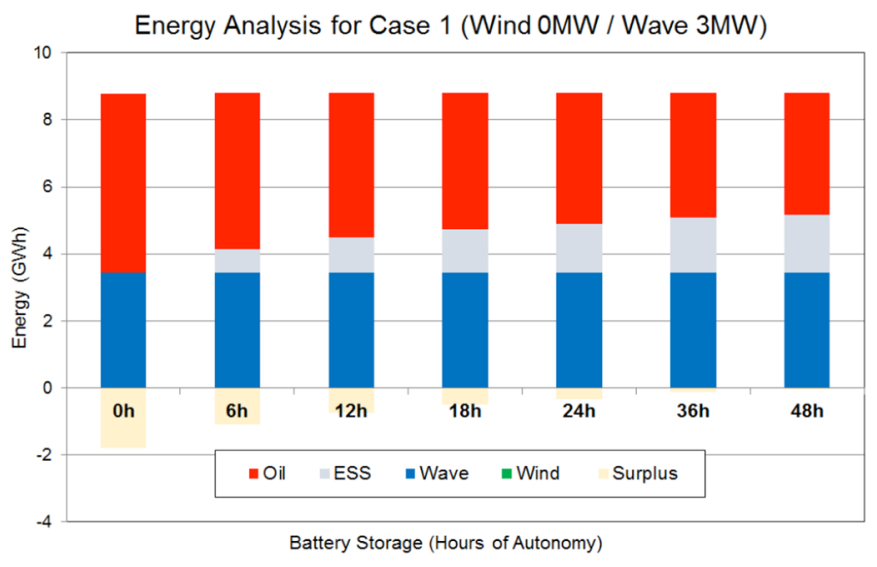

Fig. 10. Proposed solution energy analysis for case 1.

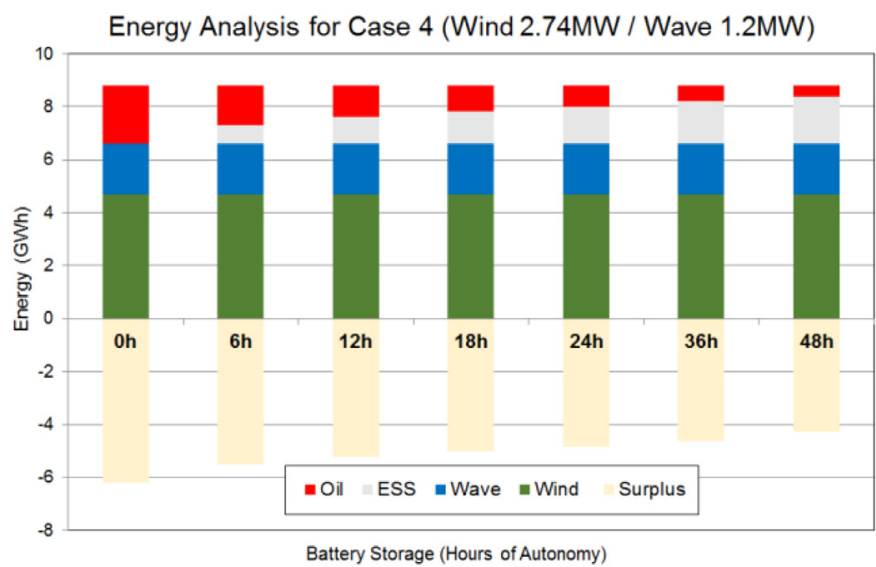

Fig. 13. Proposed solution energy analysis for case 4 .

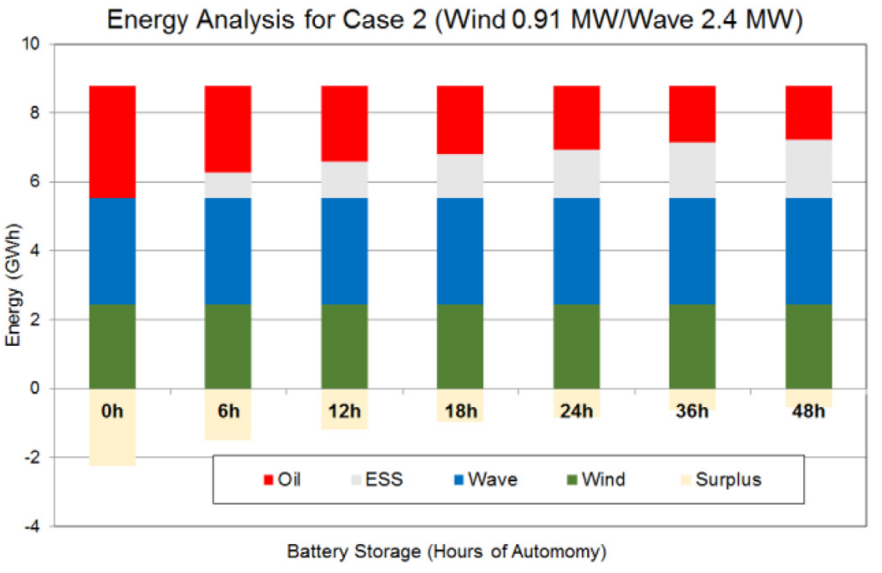

Fig. 11. Proposed solution energy analysis for case 2 .

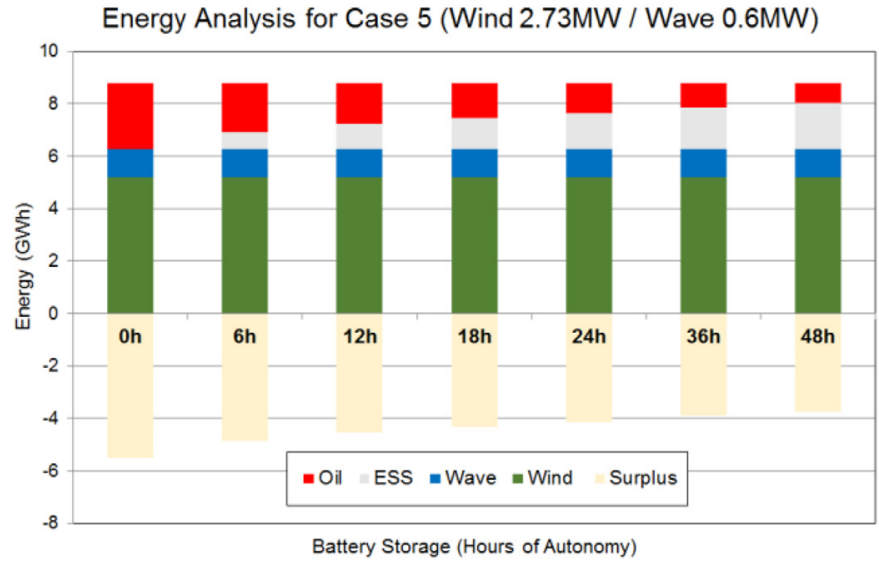

Fig. 14. Proposed solution energy analysis for case 5 .

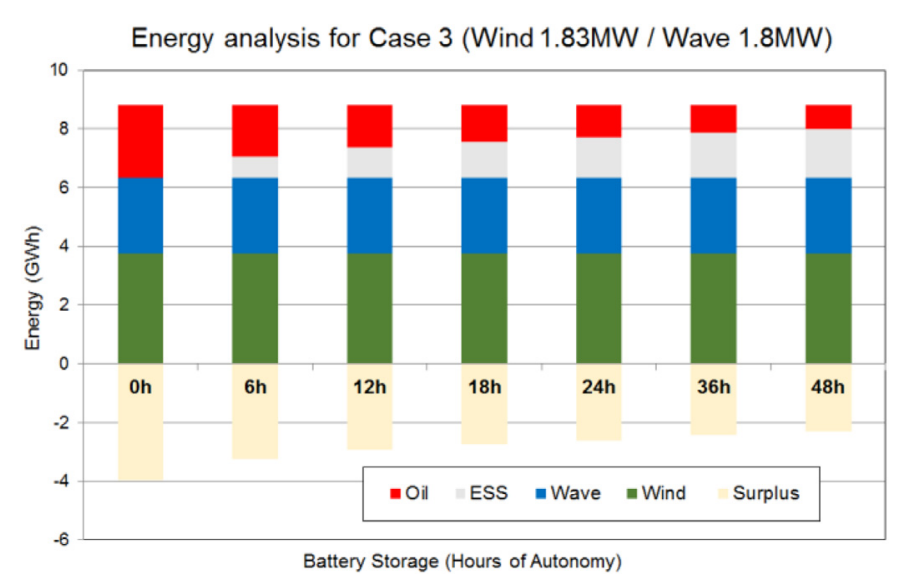

Fig. 12. Proposed solution energy analysis for case 3 .

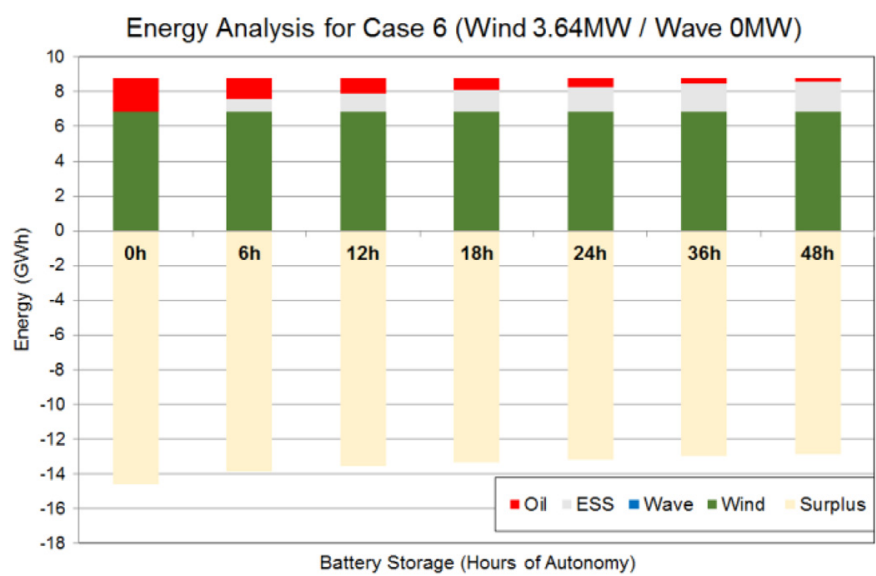

Fig. 15. Proposed solution energy analysis for case 6 . 


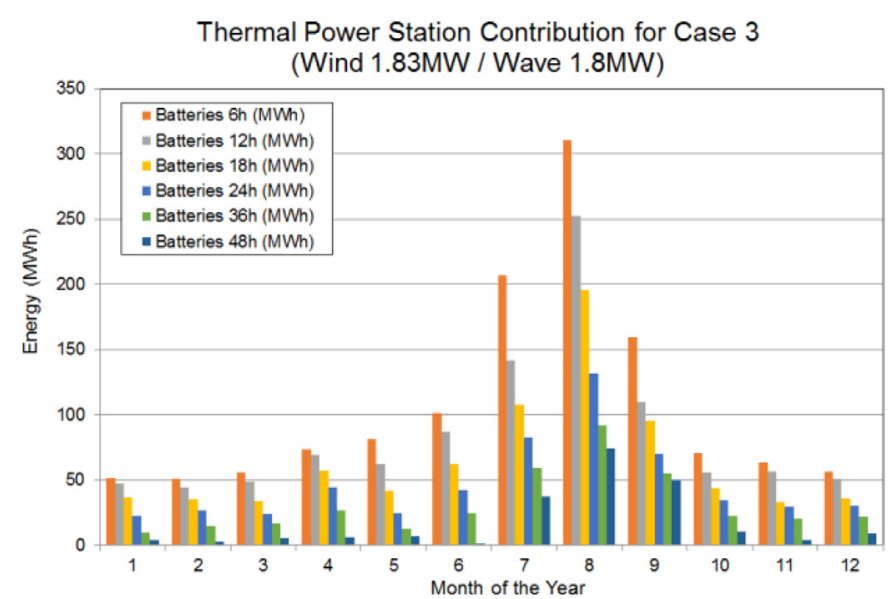

Fig. 16. Monthly oil-based energy production for the local APS vs. storage scenarios of case 3 .

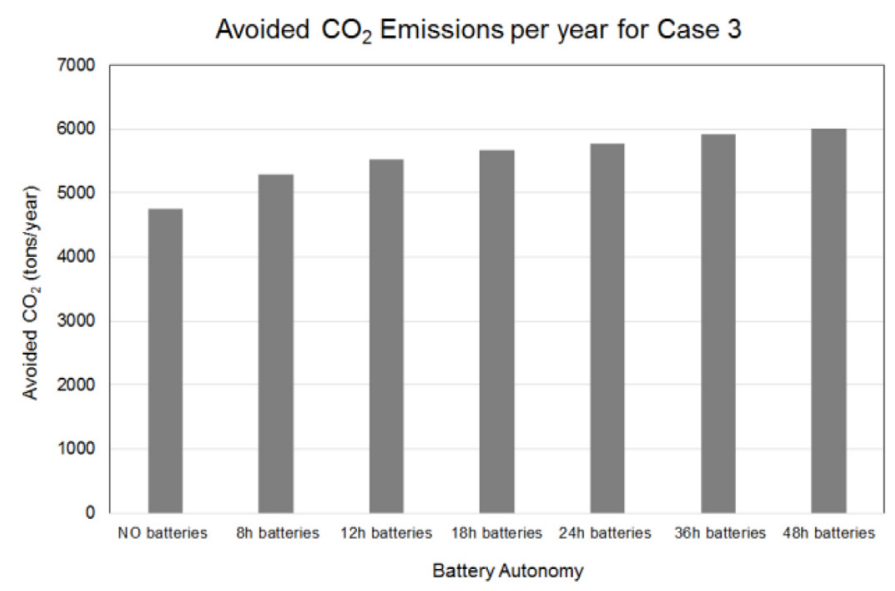

Fig. 17. Annual reduction of carbon dioxide emissions due to hybrid power station operation for case 3 .

almost $85 \%$ (see also Fig. 4). Moreover, this oil consumption reduction is accompanied by the corresponding carbon dioxide emissions decrease, Figure 17.

\section{Conclusions}

For the last decade, the presence of RES in the global energy mix is constantly rising. This is mainly due to the increased contribution of wind and solar power generation. To that end, and even though Greece has demonstrated an increase in the energy penetration of RES in the local energy mix over the last years, remote islands that are noninterconnected to the mainland grid still rely on oil-based power generation as the main source of electricity.

In the specific study, we focused on the island of Amorgos and examined a wind / wave / storage energy solution. Selection of the components has been based on commercially available products, with the aim to produce realistic scenarios and results that were then analyzed, concerning both levels of energy autonomy achieved and overall exploitation of the energy yield of each configuration. Results obtained demonstrated appreciable complementarity between the two resources (wind and wave), which if supported by a properly sized storage system is expected to generate increased levels of energy autonomy together with reasonable levels of occurring surplus.

Further work to that end, challenges sector coupling and electrification of other uses on the island that can harvest any accruing surplus and thus improve the energy and economic performance of the proposed solution. On top of that, and for all cases analyzed, considerable imported oil reduction is expected, leading at the same time to significant carbon dioxide emissions decrease.

\section{References}

1. Regulatory Authority for Energy, Energy consumption for non-interconnected islands (2020). http://www.rae.gr/site/ categories_new/electricity/market/mdn.csp

2. J.K. Kaldellis, G.T. Tzanes, C. Papapostolou, K. Kavadias, D. Zafirakis, Analyzing the limitations of vast wind energy contribution in remote island networks of the Aegean Sea Archipelagos, Energy Proc. 142, 787 (2017)

3. Research infrastructure, Poseidon system, a comprehensive marine monitoring, forecasting and information system for the Hellenic Seas, https://www.hcmr.gr/en/research-infra structures/poseidon-system (2021)

4. Monthly reports of TPS consumption, for the no-interconnected islands, https://www.deddie.gr/el/themata-tou-dia xeiristi-mi-diasundedemenwn-nisiwn/agora-mdn/stoixeiaekkathariseon-kai-minaion-deltion-mdn/miniaia-deltia-apethermikis-paragogis / minaia-pliroforiaka-deltia-paragogis2019 (2019)

5. A.M. O'Hagan, C. Huerta, J. O'Callaghan, D. Greaves, Wave energy in Europe: views on experiences and progress to date, Int. J. Mar. Energ. 14, 180-197 (2016)

6. T. Soukissian, N. Gizari, M. Chatzinaki, Wave potential of the Greek seas, WIT Trans. Ecol. Environ. 143, 203-213 (2011)

7. P. Clément McCullen, A. Falcão, A. Fiorentino, F. Gardner, K. Hammarlund, G. Lemonis, T. Lewis, K. Nielsen, S. Petroncini, M.T. Pontes, P. Schild, B.O. Sjöström, H.C. Sørensen, T. Thorpe, Wave energy in Europe: current status and perspectives, Renew. Sustain. Energy Rev. 6, 405-431 (2002)

8. G.J. Dalton, R. Alcorn, T. Lewis, Case study feasibility analysis of the Pelamis wave energy convertor in Ireland, Portugal and North America, Renew. Energy 35, 443-455 (2010)

9. Bathymetric map of Amorgos, https://www.hartis.org

10. NGK Insulators,NaS batteries. https://www.ngk-insulators. com/en/product/nas.html

11. B. Zakeri, S. Syri, Electrical energy storage systems: a comparative life cycle cost analysis, Renew. Sustain. Energy Rev. 42, 1016 (2014)

12. D. Zafirakis, J.K. Kaldellis, Determination of energy storage requirements in relation to local RES potential characteristics for the maximum contribution of RES power 
generation in Aegean Sea Island Grids, in 9th Mediterranean Conference on Power Generation, Transmission, Distribution and Energy Conversion, Athens 2-5 November 2014 (2014)
13. S. Ding, S. Yan, D. Han, Q. Ma (Eds), Overview on hybrid wind-wave energy systems, International Conference on Applied Science and Engineering Innovation (ASEI2015) (2015)

Cite this article as: Spyridon Trikalitis, George Lavidas, John K. Kaldellis, Energy Analysis of A Hybrid Wind-Wave Solution For Remote Islands, Renew. Energy Environ. Sustain. 6, 34 (2021) 